\title{
Erratum
}

\section{Macromechanics of Composites}

K.K. Chawla, Composite Materials: Science and Engineering,

DOI 10.1007/978-0-387-74365-3_11, (C) Springer Science+Business Media New York 2012

DOI 10.1007/978-0-387-74365-3_16

The equation 11.14 in Chapter 11, page 393 is incorrect. The correct equation is shown below:

$$
\begin{aligned}
& Q_{11}=\frac{S_{22}}{S_{11} S_{22}-S_{12}^{2}}, \\
& Q_{12}=-\frac{S_{12}}{S_{11} S_{22}-S_{12}^{2}}, \\
& Q_{22}=\frac{S_{11}}{S_{11} S_{22}-S_{12}^{2}}, \\
& Q_{66}=\frac{1}{S_{66}} .
\end{aligned}
$$

The online version of the original chapter can be found at http://dx.doi.org/10.1007/978-0-387-74365-3_11 